\title{
Functional Performance in Female Soccer Players Before and After Knee Injury Prevention Training
}

\author{
Linda Ytfeldt ${ }^{1,2 *}$, Sofia Skenk ${ }^{3}$, Jörgen Månsson ${ }^{4}$ and Marita Andersson Grönlund ${ }^{2}$
}

${ }^{1}$ Department of Physiokliniken Ytfeldt, Kungsbacka, Sweden

${ }^{2}$ Department of Clinical Neuroscience, Institute of Neuroscience and Physiology, Sahlgrenska Academy, University of Gothenburg, Gothenburg, Sweden ${ }^{3}$ Department of Clinical Neuroscience, Idrottsrehab Ullevi, Gothenburg, Sweden

${ }^{4}$ Department of Primary Health Care, Institute of Medicine, Sahlgrenska Academy, University of Gothenburg, Gothenburg, Sweden

\begin{abstract}
Objective: Female soccer players have an increased risk of knee injuries. Functional tests are used to evaluate global knee function after injury and/or surgery. The aims of this study were to characterize functional performance in female soccer players using four selected functional performance tests and to evaluate the effects of a specific injury prevention programme.
\end{abstract}

Methods: Ninety-nine female soccer players were divided into an intervention group $(n=53)$ and controls $(n=46)$. Both groups performed four functional performance tests at baseline and were retested at three months' follow-up. Only the intervention group was educated in knee injury prevention and given a prevention programme including three exercises recommended twice a week.

Results: At follow-up the intervention group had significantly better results in the single leg sit-to-stand test (right leg $27 \pm 7.7$ vs. $31 \pm 7.0$; left leg $28 \pm 7.0$ vs. $30 \pm 16.8$ ) than the controls (right leg $25 \pm 5.6$ vs. $26 \pm 6.6$; left leg 24 \pm 6.0 vs. $25 \pm 6.0$ ); $p=0.001 ; p<0.0001$, respectively. The intervention group also had significantly improved results in single-leg hop for distance in both legs from baseline (right leg: $116 \pm 15.2 \mathrm{~cm}$; left leg: $118 \pm 14.2 \mathrm{~cm}$ ) to follow-up (right leg: $121 \pm 14.4 \mathrm{~cm}$; left leg: $122 \pm 15.8 \mathrm{~cm}$ ); $p=0.03 ; p=0.02$, respectively.

Conclusion: This brief injury prevention programme seemed to improve muscular strength and endurance in the lower extremities of female soccer players when performed for three months and evaluated on four selected functional tests.

Keywords: Female; Functional testing; Football; Injury prevention; Knee; Lower extremity; Soccer; Women

\section{Introduction}

Over the past decade, interest in women's soccer has grown. The number of female soccer players has increased and according to the International Federation of Football Association [1], there are today 29 million women and girls playing football worldwide. The game has become faster and more powerful over time, requiring players to become more athletic $[2,3]$. Injuries in female soccer players have become more common, with most involving the lower limbs $[4,5]$ especially the ankles and knees [4,6,7].

Previous studies have shown that female athletes in sports involving twist and torque jumps have four to six times higher risks of serious knee injuries, such as anterior cruciate ligament (ACL) injuries, than male athletes in similar sports [8]. Female soccer players' risk of injury is highest during their post-pubertal years $[9,10]$ and peaks slightly earlier than males'. Anterior cruciate ligament injuries are among the most serious in soccer [6] often requiring surgery and a long period of rehabilitation. The risk of developing early osteoarthritis increases with this type of injury, and an ACL injury may lead to high costs for both the athlete and society $[8,11,12]$.

Usually, injuries in female soccer players occur without contact with other players during rapid deceleration, sudden change of direction, or a bad landing after a jump [4,9,12-14]. Female athletes have a movement pattern different to males, with less use of the knee flexor muscles and increased adduction and abduction moments at the knee when landing or cutting [8]. Excessive valgus movement of the knee is an indicated risk factor for ACL injury $[8,15]$. When testing strength and functional performance males have shown better results compared to females, however no differences in limb symmetry indexes (LSIs) were found between genders [16].

Several studies have shown that knee injuries among women athletes may be reduced by using neuromuscular training programmes, strength training, proprioception and balance training and plyometric training [8,17-23]. Multi-component preventive programs seem to be more effective than single-component programmes [24]. A Swedish preventive exercise programme was shown to reduce knee injuries in female soccer players by $77 \%$ [17] and a national prevention programme for knee injuries in Switzerland reduced injury rates in amateur soccer players and showed both social and economic cost-benefits [25].

Functional tests are often used by physiotherapists to assess knee function after injury and to obtain reliable measures of lower extremity performance and LSIs [26-30]. The prevention of sports injuries is not currently implemented in health care even though sports injuries represent a large proportion of particularly serious knee injuries. The prevention of knee injuries has mostly been studied and evaluated in group samples $[10,17,18]$ and no consensus has been reached on which

*Corresponding author: Linda Ytfeldt, Department of Clinical Neuroscience, Institute of Neuroscience and Physiology, Sahlgrenska Academy, University of Gothenburg, Gothenburg, Sweden, Tel: +46705859678; E-mail: info@fysioklinikenytfeldt.se

Received: July 04, 2018; Accepted: August 03, 2018; Published: August 09, 2018

Citation: Ytfeldt L, Skenk S, Månsson J, Grönlund MA (2018) Functional Performance in Female Soccer Players Before and After Knee Injury Prevention Training. Physiother Rehabil 3: 161. doi: 10.4172/2573-0312.1000161

Copyright: $@ 2018$ Ytfeldt L, et al. This is an open-access article distributed under the terms of the Creative Commons Attribution License, which permits unrestricted use, distribution, and reproduction in any medium, provided the original author and source are credited. 
specific parameters or key components truly explain the resulting reduction in injury rates. Better understanding of the mechanisms of prevention training programmes would benefit both athletes and society by increasing the use of prevention in primary care to avert sports injuries.

The aim of this study was to characterize functional performance in female soccer players using four selected functional performance tests and to evaluate the effects of a specific injury prevention programme on endurance, jumping and landing techniques, balance and explosive strength, and assess which mechanism that seems to be the most responsive one.

\section{Materials and Methods}

\section{Study population}

Of eight female soccer teams in the southwest of Sweden invited to take part in this prospective, controlled intervention study, six agreed to participate. Inclusion criteria were active female amateur soccer players over 13 years of age with no current injury and participating in fully in training and matches. The exclusion criterion was any lower limb injury lasting for more than three months during the past year. To prevent potential confounding the participating teams were strategically selected into an intervention group (IG) and a control group (CG) roughly matched for number of players, geographic location, and season of the year for performing the functional testing.

\section{Procedure}

Four functional tests measured endurance, jumping and landing techniques, balance and explosive strength:

1. The single leg sit-to-stand test;

2. The side hop test;

3. The standing on one leg eyes closed (SOLEC) balance test and

4. The single leg hop for distance test (Figures 1a-1d).

All tests were conducted by two physiotherapists (LY and SK). The physiotherapist gave standardized instructions before each test and

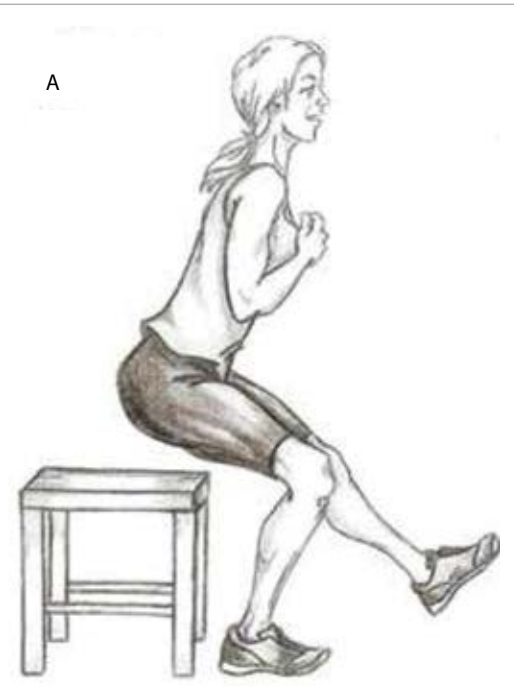

Figure 1a: The functional performance tests used in the study: (1a) single leg sit-to-stand.

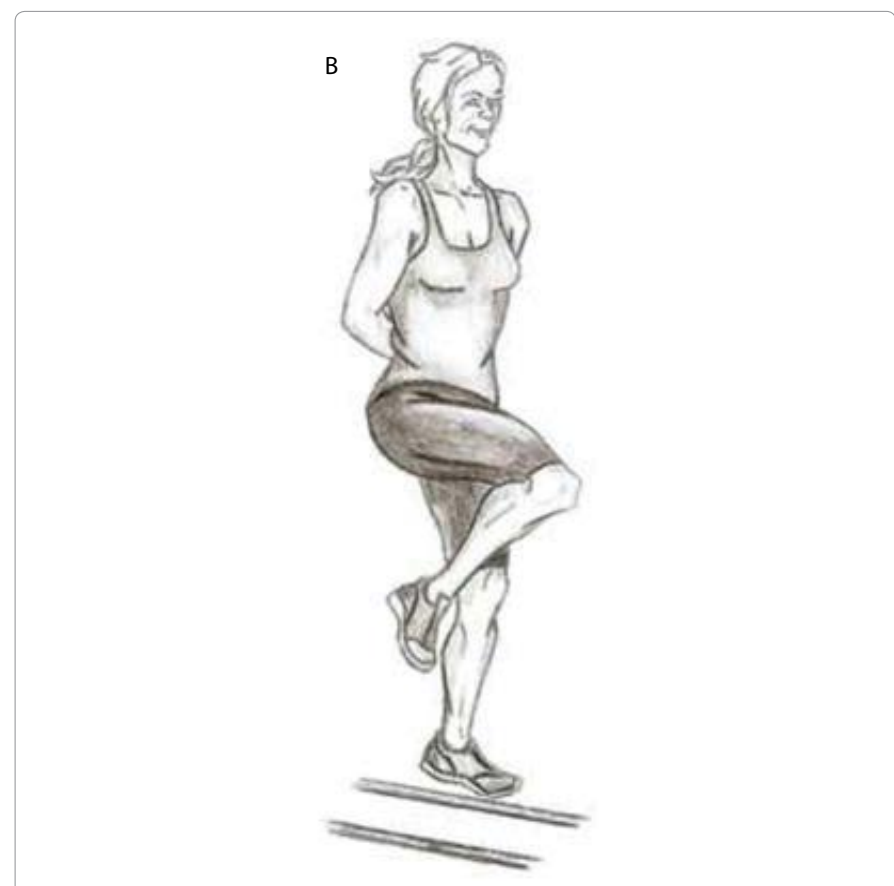

Figure 1b: The functional performance tests used in the study: (1b) side hop.

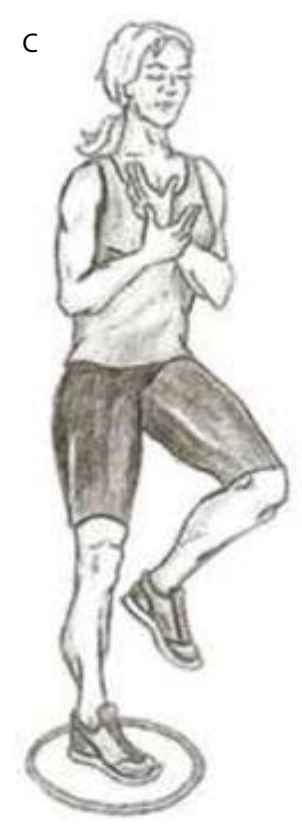

Figure 1c: The functional performance tests used in the study: (1c) standing on one leg eyes closed (balance).

refrained from encouraging participants during the test sessions. The participants were given a few minutes before each test for familiarization of the test. The tests were performed as follows:

\section{The single leg sit-to-stand test}

The participants were started sitting on a bench with arms crossed over their chest. They were instructed to rise from sitting to standing position on one leg as many times as possible in 60 seconds. They were not allowed to touch the floor with the other leg, which was held straight 


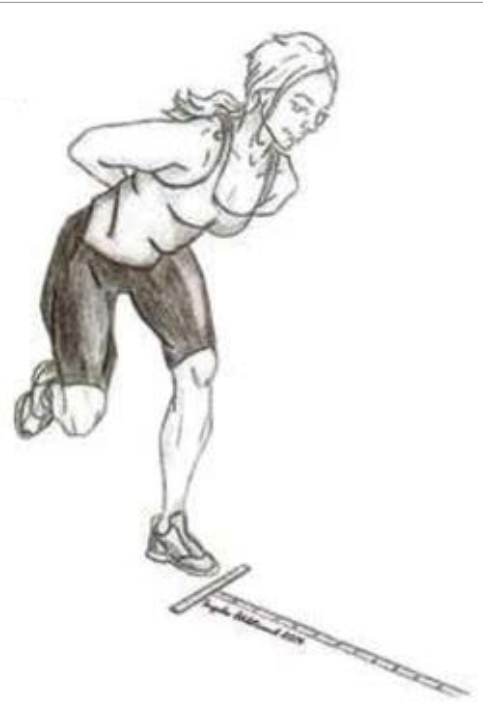

Figure 1d: The functional performance tests used in the study: (1d) single leg hop (distance) test.

in front of them. The test was performed with full muscle control, i.e. the eccentric phase was carried out with constant speed, and the concentric phase without trunk and arm movements (Figure 1a). This test, with the exception of the time limit, was the test previously used by Thorstensson et al. [31]. It was used to evaluate strength and endurance in thigh muscles.

\section{The side hop test}

Two lines, $40 \mathrm{~cm}$ apart on the outer sides, were marked on the floor. Participants stood on one leg just outside one line, with their hands behind their back. On a signal they were to jump on one leg from one side to the other without touching the lines marked on the floor. The goal was to perform as many complete side hops as possible in 30 seconds (Figure 1b). One attempt was allowed for each leg. The side hop was used to evaluate jumping technique and endurance, and has been shown to have good reliability [32].

\section{The SOLEC balance test}

Participants stood on one leg in a circle $50 \mathrm{~cm}$ in diameter with arms folded over the chest. The free leg was held up with $90^{\circ}$ flexion in both knee and hip. With eyes closed, the task was to maintain balance as long as possible within the circle to a maximum time of 60 seconds. Movements within the circle were allowed. The test was discontinued if the participant touched the circle (with the foot of the standing leg) or the floor (with foot of the free leg) (Figure 1c). Participants were allowed three attempts per leg, and the best result for each leg was recorded [26]. The SOLEC balance test was used to evaluate balance, and the test has good reliability [33] and may be appropriate for measuring change in balance at a group level [34].

\section{The single-leg hop for distance test}

Participants stood on one leg with their toes behind a line marked on the floor. Free leg swing with the other leg was allowed. Hands were placed behind the back. Participants were instructed to hop forward as far as possible while performing a controlled and balanced landing. The single leg hop for distance was measured in $\mathrm{cm}$, from toe to heel (Figure 1d) [32,35]. Three attempts were documented for each leg and the longest successful jump was recorded. Single leg hop for distance was used to evaluate explosive strength and has a good reliability [35]. It has also proved to be a useful tool in identifying athletes at risk for low back or lower extremity injuries [36]. Both groups were tested twice, first at baseline and then at three months follow-up, using the same four functional tests at both sessions. The IG also performed an extra test, the drop jump test, at baseline. Participants were instructed to jump down from a box $30 \mathrm{~cm}$ high and to perform a maximal vertical jump directly after landing. They were instructed to try to land on both feet with knee alignment [27]. This was repeated three times for each person. The test was performed in front of a mirror to provide the participant with direct visual feedback, and the physiotherapist assessed the jumps subjectively and gave participants additional feedback. During the first session, participants in the IG were also given a lecture including information about knee anatomy, injury mechanisms, and the importance of prevention through training such as practicing good knee alignment and exaggerated hip and knee flexion on landing. They were further instructed to perform three exercises twice a week at home and record the training sessions in a training log (Table 1). The IG coaches were instructed orally and in writing about the following recommended exercises to include during soccer practice: running forward, running backwards side jumps, zigzag shuffles, long jumps (16 jumps $\times 3$ sets), walking lunges (20 steps $\times 3$ sets), square jumping (forward, to the side, backward , and to the other side; 5 repetitions $\times$ 2 sets), balance training (standing on one leg, in pairs of two, and the players try to push each other off balance; $30 \mathrm{~s}$ per leg $\times 2$ sets). These exercises were recommended once or twice per week and suggested as a part of the warm-up.

The CG was tested at baseline on the same functional tests and in the same way as the IG, except they were not asked to do the drop jump test. The CG participants were not given any lecture or home exercise programme, nor were their coaches asked to alter their warm-up and training routines. CG participants were informed that they would receive the same information and training protocol as the IG after the study was finished. During the three months of the study, all participants in both groups self-reported any injury involving the lower extremities that was incurred during training or playing soccer and that prevented participation in training or playing for at least two consecutive days.

\section{Statistical analysis}

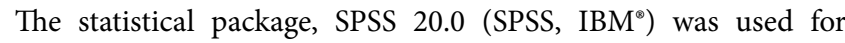

\begin{tabular}{|c|c|c|}
\hline Exercises & Description & Repetitions \\
\hline Walking lunges & $\begin{array}{c}\text { Walking lunges with straight arms above } \\
\text { head with a focus on postural control and } \\
\text { knee stability. }\end{array}$ & $\begin{array}{c}16 \text { steps (8 steps } \\
\text { per leg) } \times 3 \\
\text { repetitions }\end{array}$ \\
\hline "The Dragon" & $\begin{array}{c}\text { Standing on one leg with light knee } \\
\text { flexion and the trunk muscles activated. } \\
\text { The back folds forward and the bottom } \\
\text { are pushed back. The hips aim to be } \\
\text { parallel to the horizontal plane. Flexion } \\
\text { in the hip and the free leg is held } \\
\text { extended behind the body. The back } \\
\text { flips to horizontal where the rear leg is in } \\
\text { line with the back. Then slowly return to } \\
\text { starting position. }\end{array}$ & $\begin{array}{c}12 \text { times (6 times } \\
\text { per leg) } \times 3 \\
\text { repetitions }\end{array}$ \\
\hline $\begin{array}{c}\text { Horizontal and } \\
\text { vertical jumps }\end{array}$ & $\begin{array}{c}\text { Tolloworizontal jumps with both feet } \\
\text { landing technique. The knee in a good } \\
\text { alignment and with an exaggerated } \\
\text { flexion in hip, knee and trunk. }\end{array}$ & $\begin{array}{c}5 \text { times } \times 2 \\
\text { repetitions }\end{array}$ \\
\hline
\end{tabular}

Table 1: Exercises, description, and repetitions of each exercise that female soccer players in the intervention group were instructed to perform at home twice a week. 
Citation: Ytfeldt L, Skenk S, Månsson J, Grönlund MA (2018) Functional Performance in Female Soccer Players Before and After Knee Injury Prevention Training. Physiother Rehabil 3: 161. doi: 10.4172/2573-0312.1000161

Page 4 of 8

statistical analysis. Means, standard deviations (SD), medians, and ranges were calculated for descriptive purposes. Paired t-test (continuous variables) was used for comparison between two occasions when separate analyses were performed for intervention participants and controls. Student's t-test was performed by comparing the means of two independent groups. For dichotomous variables, we used Fisher's exact test. Test results were considered significant at $\mathrm{p}<0.05$.

The study was approved by the regional ethics committee in Stockholm, Sweden, No 2011/1213-31/2. The conduct of the study adhered to the tenets of the Helsinki declaration. Informed consent was obtained from all young adults from the age of 18 and the parents of all the children and younger adolescents participating in the study.

\section{Results}

In total, 137 subjects from six female soccer teams agreed to participate in the study. Eight players were excluded due to injury or illness and a total of 99 players (77\%) completed the study. The final sample at follow-up consisted of 53 players with a mean age of 16.4 years (range 13.7-28.9 years) in the IG and 46 players with a mean age of 16.2 years (range 13.1-33.9 years) in the CG. The drop-out rate was $17 / 70(24 \%)$ for the IG and 13/59 (22\%) for the CG (Figure 2).

\section{Test results at baseline and follow-up}

Table 2 shows the results from the four selected functional performance tests at baseline and follow-up. Baseline test results were similar for the two groups, with no significant between-group differences except for the IG's higher score on the single leg sit-to-stand test for the left leg. In the IG, 46/53 (87\%) players stood for 60 seconds on at least one leg in the SOLEC balance test; the corresponding figure for the CG was 40/46 (87\%) players.

At three months follow-up significant differences were found between the groups. The IG had higher scores on single leg sit-to-stand

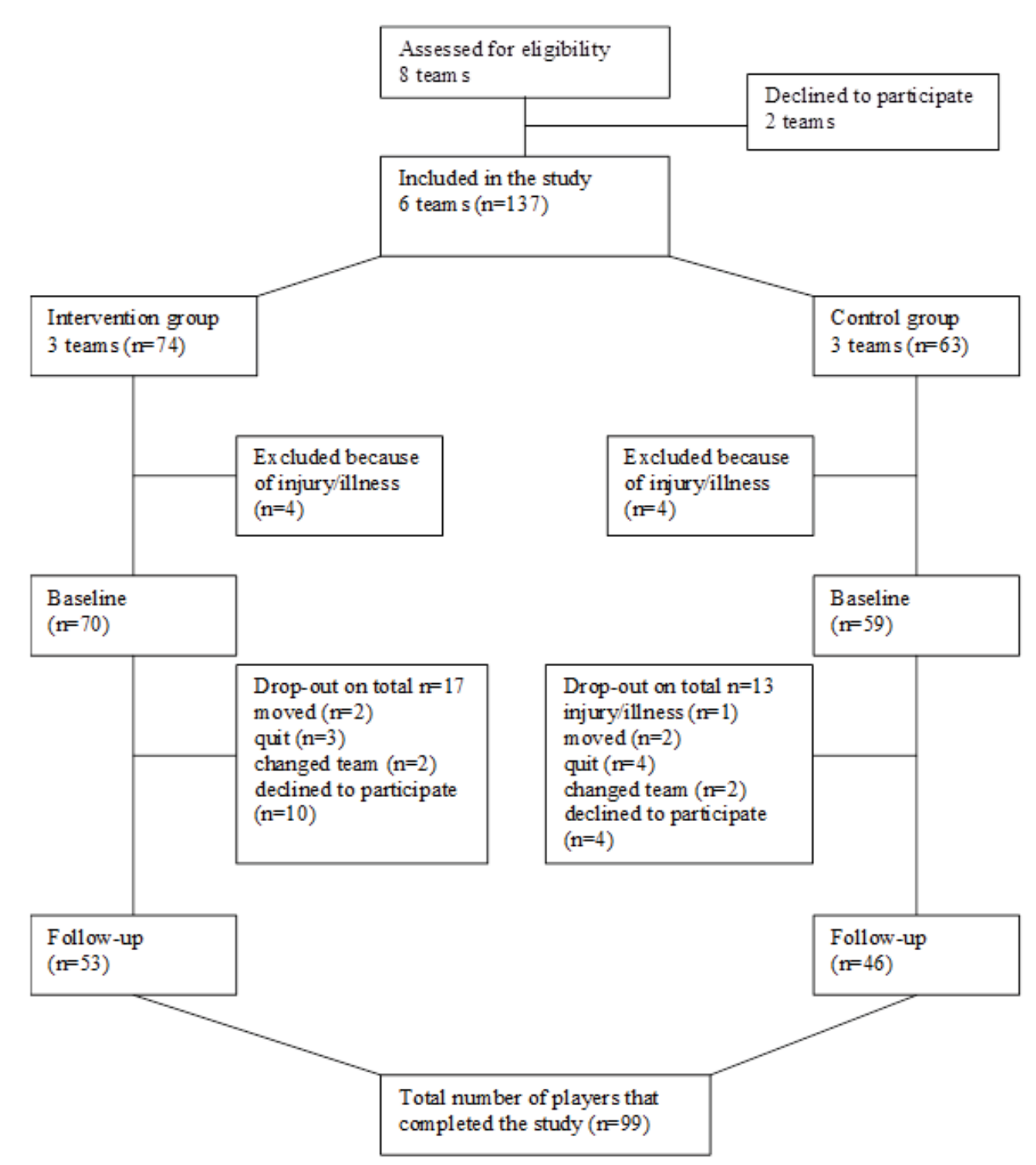

Figure 2: Flow chart showing the study design and study sample from invitation to completed study. 


\begin{tabular}{|c|c|c|c|c|c|c|}
\hline Tests & $\begin{array}{c}\text { At Baseline } \\
\text { Intervention group } \\
(n=53)^{\star} \text { Mean (SD) }\end{array}$ & $\begin{array}{c}\text { Control group }(n=46) \\
\text { Mean (SD) }\end{array}$ & p-value & $\begin{array}{c}\text { At Follow-up } \\
\text { Intervention group } \\
(n=53)^{*} \text { Mean (SD) }\end{array}$ & $\begin{array}{c}\text { Control group } \\
(n=46) \text { Mean (SD) }\end{array}$ & p-value \\
\hline Single leg sit-to-stand $(n)$ right & $27( \pm 7.7)$ & $25( \pm 5.6)$ & 0.12 & $31( \pm 7.0)(n=52)$ & $26( \pm 6.6)$ & 0.001 \\
\hline Single leg sit-to-stand $(n)$ left & $28( \pm 7.0)$ & $24( \pm 6.0)$ & 0.005 & $30( \pm 6.8)$ & $25( \pm 6.3)$ & 0.001 \\
\hline Side hop $(n)$ right & $36( \pm 11.5)(n=52)$ & $34( \pm 12.3)(n=45)$ & 0.47 & $38( \pm 11.2)(n=52)$ & $36( \pm 12.6)$ & 0.42 \\
\hline Side hop (n) left & $36( \pm 11.1)(n=51)$ & $32( \pm 11.8)$ & 0.07 & $38( \pm 11.1)(n=51)$ & $34( \pm 12.8)$ & 0.07 \\
\hline SOLEC (s) right & $51( \pm 15.4)$ & $56( \pm 10.9)$ & 0.09 & $54( \pm 12.5)$ & $56( \pm 10.6)$ & 0.31 \\
\hline SOLEC (s) left & $53( \pm 13.2)$ & $56( \pm 8.4)$ & 0.18 & $54( \pm 13.2)$ & $59( \pm 4.0)$ & 0.02 \\
\hline Single leg hop for distance $(\mathrm{cm})$ right & $116( \pm 15.2)(n=52)$ & $118( \pm 21.2)$ & 0.62 & $121( \pm 14.4)(n=52)$ & $119( \pm 14.7)$ & 0.69 \\
\hline Single leg hop for distance $(\mathrm{cm})$ left & $118( \pm 14.2)$ & $119( \pm 21.4)$ & 0.94 & $122( \pm 15.8)$ & $119( \pm 16.1)$ & 0.4 \\
\hline \multicolumn{7}{|c|}{$\begin{array}{l}\text { *Where numbers differ from the total number of children in the group, they are given separately for each category. } \\
\text { cm=centimetres; } n=\text { number; s=seconds; } S D=S \text { Standard Deviation; SOLEC=standing on one leg eyes closed. } \\
\text { P-values were obtained by Student's t-test. }\end{array}$} \\
\hline
\end{tabular}

Table 2: Results of functional testing at baseline and follow-up, comparing the intervention group and controls.

\begin{tabular}{|c|c|c|c|c|c|}
\hline Tests: intervention group $(n=53)$ & Change (\%) & p-value & Tests: control group $(n=46)$ & Change (\%) & p-value \\
\hline Single leg sit-to-stand $(n)$ right & 14 & 0.001 & Single leg sit-to-stand $(n)$ right & 6 & 0.008 \\
\hline Single leg sit-to-stand $(n)$ left & 10 & 0.001 & Single leg sit-to-stand $(n)$ left & 6 & 0.001 \\
\hline Side hop $(n)$ right & 6 & 0.16 & Side hop $(n)$ right & 6 & 0.07 \\
\hline Side hop (n) left & 6 & 0.19 & Side hop (n) left & 6 & 0.05 \\
\hline SOLEC (s) right & 5 & 0.25 & SOLEC (s) right & 1 & 0.736 \\
\hline SOLEC (s) left & 1 & 0.75 & SOLEC (s) left & 4 & 0.064 \\
\hline Single-leg hop for distance $(\mathrm{cm})$ right & 4 & 0.03 & Single-leg hop for distance $(\mathrm{cm})$ right & 1 & 0.459 \\
\hline Single-leg hop for distance $(\mathrm{cm})$ left & 3 & 0.02 & Single-leg hop for distance $(\mathrm{cm})$ left & 1 & 0.729 \\
\hline
\end{tabular}

Table 3: Relative change in test results from baseline to follow-up for the intervention group and the control group.

test for both right and left legs ( $\mathrm{p}=0.001$, respectively). There were also significant differences in the test results for the SOLEC balance test for the left leg (mean values), on which the CG had better results than the IG ( $\mathrm{p}=0.015)$. In the IG 48/52 (92\%) players were able to stand 60 seconds on at least one leg and the corresponding figure for the CG was $43 / 46$ (93\%) players. However, the median value for the IG was 60 seconds (range 13-60 s) for both right and left legs, and for the CG it was also 60 seconds for each leg (range 43-60 s).

\section{Relative change from baseline to follow-up}

Table 3 shows significantly improved results in the single-leg hop for distance test and the single leg sit-to-stand test for both legs in the IG. An improvement was also found in the CG on single leg sit-to-stand test for both legs. However, the improvement in the CG was not as great as it was in the IG $(6 \%$ vs. $14 \%$ in the right leg and $6 \%$ vs. $10 \%$ in the left leg).

\section{Self-reported data}

Fifty-eight percent $(31 / 53)$ of the players in the IG reported the number of exercise sessions they performed during the three-month follow-up. The median number of completed sessions was 15 (range 4-41). Eighty-three percent (44/53) of the participants in the IG reported the number of injuries compared with $37 / 46$ (80\%) in the CG. The number of players that self-reported injuries $(n=18)$ during the follow-up were equally distributed, with 9 in both the IG (9/44; $20 \%)$ and the CG $(9 / 37 ; 24 \%)$. The total number of injuries reported in the IG was 10 (foot $n=3$; thigh $n=2$; knee $n=4$; hip $n=1$ ). The equal number of injuries was reported in the CG (foot $n=6$; lower leg $n=2$; knee $n=2)$. There was no significant difference between the groups regarding number of players injured during the study period $(\mathrm{p}=0.79$, Fisher's exact test).

\section{Discussion}

The main findings of this study showed significantly better results in the IG than the CG on the single leg sit-to-stand test for both legs at the three-month follow-up. There were also statistically significant improvements in the IG from baseline to follow-up in single-leg hop for distance (both legs), which were not found in the CG. These improvements, indicating increased muscular strength and endurance in the lower extremities, were most certainly due to the effects of the injury prevention training programme.

The outcome of interest in the present study was improved functional performance after specific injury prevention training for lower limb, evaluated by four selected functional tests. Strength and endurance in lower extremity seems to be the most responsive mechanisms in this population of young female soccer players. Previous injury prevention studies in soccer players have mostly used injury rates as the outcome of interest $[17,18,20,23,37]$. Several studies have shown that the risk of injury among women athletes can be reduced by a preventive exercise programme $[4,8,17,18,23]$. In the present study the population was too small and the follow-up too short to draw any conclusions about the frequency of injury after the intervention period, although all injuries were reported.

A considerable amount of time was spent to educate and enforce awareness of injury mechanisms among the participants. For example, the Drop Jump test was performed in front of a mirror to increase understanding and compliance of the programme. Orr et al. [38] studied how well-known the effects of injury prevention training are in young female soccer players and their coaches and parents. They found that less than half of the players, $50 \%$ of the parents, and $62 \%$ of the coaches thought that it was possible to prevent knee injuries through specific injury prevention training. It is very important to inform 
young athletes, their coaches, and their parents about the benefits of prevention training. An interaction with a physical therapist during pre-season training would improve the identification of individual risk factors [39]. The prepubertal and pubertal years are very favorable for learning and practicing motor skills, techniques, and movement patterns [40] and it is easier to integrate injury prevention training as a part of soccer training when players are young [41]. Most subjects $(n=57)$ in the present study were aged 13 to 15 .

The total drop-out rate in the study was 30/129 (23\%), and it was attributable to several causes. Many young athletes withdraw from sports during their teen years, and young female athletes are most likely to withdraw during their early teens [42]. The players in this study were given a diary to report their training sessions which is an obvious limitation. Furthermore, compliance with the injury prevention program was unsatisfying; only $58 \%$ of the players reported the number of exercise sessions they completed. Soligard et al. [41] have shown that players with a positive attitude towards injury prevention are correlated with high compliance and less risk of injury. The importance of understanding factors such as motivation that affect players and coaches has also been highlighted [25]. Educating coaches is fundamental and increases the adoption rate of prevention training programme during soccer practice $[42,43]$. Providing the players with easily accessible and up-to-date information and reminders via text messages or an interactive cell phone application would probably improve compliance by giving players additional motivation to continue the training. This is suggested as a complement to ordinary injury prevention training programmes.

A limitation of this study was the lack of standard preparation before each test session. Some of the players had had soccer practice earlier in the day and/or had played a match the day before. However, this chance was no different between groups or test sessions. The home exercise programme was instructed only once, at baseline. The effects of this programme depended on the subject's commitment and the quality with which the exercises were performed. There was no control or monitoring of how the participants performed the programme. The results of the study might have been different had a physiotherapist been present to supervise exercises during soccer training sessions.

The programme consisted of three exercises to allow participants to perform it twice a week without it taking too much time or effort. Players' ability to memorize the exercises also increased when the programme was not too long. To make the training programme easy to implement during soccer training, or even at home, all the exercises were performed in the standing position and required no additional equipment. Standing position is also more specific to soccer than, for example, supine or sitting positions. All components trained in the three selected exercises in this study-thigh and core strength, proprioception, and body control-have been shown to have a preventive effect on injuries $[9,44]$. Exercises for balance and jumping technique have also been reported to be effective for preventing knee injuries in particular [8].

Functional tests were used to measure physical performance and to increase the motivation of the participants to continue with the prevention training. Functional tests are more specific to particular sports than other measures such as laboratory tests [45]. The functional tests used in this study are frequently used for lower extremities by physiotherapists in everyday clinic. They are often used to evaluate whether full functional performance is regained after a period of rehabilitation. Unilateral testing should be used to identify deficits or asymmetries in performance [46]. Side hop test has high difficulty as it requires good knee stability while the muscle is fatigued [41] and this test gave a clear measurement of the participants' physical performance. Balance was evaluated to assess the combination of peripheral vestibular and visual properties [47]. Measuring balance in standing has been shown to have strong value for predicting sports injuries [48]. Steffen et al. [21] showed that injury prevention training improved functional balance and reduced injury risk in soccer players. In the present study the balance test, SOLEC, turned out to be too easy for the young female soccer players to provide a useful measurement. Too many of the participants were able to stand on one leg with eyes closed for 60 seconds. This test would have to be more difficult to provide a clearer result. The three allowed attempts for each subject gave further misleading results when there is obviously a difference between succeeding for 60 seconds on three attempts versus on only one attempt. A possible variation would be to calculate the mean value of the three attempts or to increase time limit for each test. We found that the single-leg sit to stand test was difficult to standardize with regard to how much arm and trunk movement was permitted. The height of the subject is also important as this test is performed standing from a bench of standard height. On the other hand, the individual's own test results between baseline and follow-up were studied, and the height of the bench would have no influence on those results. Physical performance is affected by a number of internal and external factors as well as gender [16]. Among other things, coordinative, physical, and psychological characteristics are all important to a player's performance [49].

\section{Conclusion}

The results in this study underline the importance to regularly conduct prevention training and especially strength training for lower extremities in female soccer players. The present study also indicate that functional testing may be a valid instrument for prevention training and a useful tool for screening for deficient physical performance in young female athletes.

At three months follow-up, there was a significant difference between the two groups, with the IG having better results on the single leg sit-to-stand test in both right and left leg, indicating improved strength and endurance in the thighs. A significant improvement was also found in the single-leg hop for distance test in the IG between baseline and follow-up, indicating increased explosive strength. This concise and modest preventive training programme, in combination with instructions and education regarding risk factors and injury prevention training, may improve physical performance with relatively little effort, and possibly, in the long run, be enough to reduce the risk of lower limb injury in female soccer players.

\section{Acknowledgements}

The authors would like to thank all the coaches and players who participate in the study. We would also like to thank Amir Baigi, M.D, Ph.D., Department of Research and Development Region of Halland, Sweden, for contributions to the statistical analyses and Ingela Ahlstrand for illustrations.

\section{Financial Supports}

The study was financially supported by Capio Health Care, Sweden.

\section{References}

1. FIFA (2018) FIFA U-20 women's world cup

2. Haugen T, Tønnessen E, Hisdal J, Seiler S (2014) The role and development of sprinting speed in soccer. Int J Sports Physiol Perform 9: 432-441.

3. Hoff J, Helgerud J (2004) Endurance and strength training for soccer players: physiological considerations. Sports Med 34: 165-180. 
Citation: Ytfeldt L, Skenk S, Månsson J, Grönlund MA (2018) Functional Performance in Female Soccer Players Before and After Knee Injury Prevention Training. Physiother Rehabil 3: 161. doi: 10.4172/2573-0312.1000161

4. Faude O, Junge A, Kindermann W, Dvorak J (2005) Injuries in female soccer players: a prospective study in the German national league. Am J Sports Med 33: $1694-1700$.

5. Jacobson I, Tegner $Y$ (2007) Injuries among Swedish female elite football players: a prospective population study. Scand J Med Sci Sports 17: 84-91.

6. Ekstrand J, Karlsson J (1998) Football medicine. Ödeshög: Svenska fotbollsförlaget $A B$.

7. Söderman K, Adolphson J, Lorentzon R, Alfredson H (2001) Injuries in adolescent female players in european football: a prospective study over one outdoor soccer season. Scand J Med Sci Sports 11: 299-304.

8. Hewett TE, Lindenfeld TN, Riccobene JV, Noyes FR (1999) The effect of neuromuscular training on the incidence of knee injury in female athletes: a prospective study. Am J Sports Med 27: 699-706.

9. Pfeiffer RP, Shea KG, Roberts D, Grandstrand S, Bond L (2006) Lack of effect of a knee ligament injury prevention program on the incidence of noncontact anterior cruciate ligament injury. J Bone Joint Surg Am 88: 1769-1774.

10. Waldén M, Hägglund M, Werner J, Ekstrand J (2001) The epidemiology of anterior cruciate ligament injury in football (soccer): a review of the literature from a gender-related perspective. Knee Surg Sports Traumatol Arthrosc 19: 3-10.

11. Lohmander LS, Ostenberg A, Englund M, Roos H (2004) High prevalence of knee osteoarthritis, pain, and functional limitations in female soccer players twelve years after anterior cruciate ligament injury. Arthritis Rheum 50: 31453152 .

12. Von Porat A, Roos EM, Roos H (2004) High prevalence of osteoarthritis 14 years after an anterior cruciate ligament tear in male soccer players: a study of radiographic and patient relevant outcomes. Ann Rheum Dis 63: 269-273.

13. Mandelbaum BR, Putukian M (1999) Medical concerns and specificities in female soccer players. Sci Sport 14: 254-560.

14. Söderman K, Pietlä T, Alfredson H, Werner S (2002) Anterior cruciate ligament injuries in young females playing soccer at senior levels. Scand J Med Sci Sports 12: 65-68.

15. Olsen OE, Myklebust G, Engebretsen L, Bahr R (2004) Injury mechanisms for anterior cruciate ligament injuries in team handball: a systematic video analysis. Am J Sports Med 32: 1002.

16. Lisee C, Slater L, Hertel J, Hart JM (2018) Effect of sex and level of activity on lower extremity strength, functional performance and limb symmetry. J Sport Rehabil 24: 1-26.

17. Kiani A, Hellquist E, Ahlqvist K, Gedeborg R, Michaelsson K, et al. (2010) Prevention of soccer-related knee injuries in teenaged girls. Arch Intern Med 170: 43-49.

18. Soligard T, Myklebust G, Steffen K, Holme I Silvers H (2008) Comprehensive warm-up programme to prevent injuries in young female footballers: cluster randomised controlled trial. BMJ 337: a2469.

19. Leetun DT, Ireland ML, Willson JD, Ballantyne BT, Davis IM (2004) Core stability measures as risk factor for lower extremity injury in athletes. Med Sci Sports Exerc 36: 926-934.

20. Mandelbaum BR, Silvers HJ, Watanabe DS, Knarr JF, Thomas SD, et al (2005) Effectiveness of a neuromuscular and proprioceptive training program in prevention anterior cruciate ligament injuries in female athletes. 2-year follow-up. Am J Sports Med 33: 1003-1010.

21. Steffen K, Emery CA, Romiti M, Kang J, Bizzini M, et al. (2013) High adherence to a neuromuscular injury prevention programme (FIFA 11+) improves functional balance and reduces injury risk in Canadian youth female football players: a cluster randomised trial. Br J Sports Med 47: 794-802.

22. Grindstaff TL, Hammill RR, Tuson AE, Hertel J (2006) Neuromuscular control training programs and noncontact anterior cruciate ligament injury rates in female athlete: a numbers-needed-to-treat analysis. J Athl Train 41: 450-456.

23. Grimm NL, Jacobs JC, Kim J, Denney BS, Shea KG (2015) Anterior cruciate ligament and knee injury prevention programs for soccer players: a systematic review and meta-analysis. Am J Sports Med 43: 2049-2056.

24. Alentorn-Geli E, Myer GD, Silvers HJ (2009) Prevention of non-contact anterior cruciate ligament injuries in soccer players. Part 2: a review of prevention programs aimed to modify risk factors and to reduce injury rates. Knee Surg Sports Traumatol Arthrosc 17: 859-879.
25. Junge A Lamprecht $M$, Stamm $\mathrm{H}$, Hasler $\mathrm{H}$, Bizzini M, et al. (2011) Countrywide campaign to prevent soccer injuries in swiss amateur players. Am J Sports Med 39: 57-63.

26. Bolgla LA, Keskula DR (1997) Reliability of lower extremity functional performance tests. J Orthop Sports Phys Ther 26: 138-142.

27. Redler LH, Watling JP, Dennis ER, Swart E, Ahmad CS (2016) Reliability of a field-based drop vertical jump screening test for $A C L$ injury risk assessment. Phys Sportsmed 44: 46-52.

28. Gokeler A, Welling W, Zaffagnini S, Seil R, Padua D (2017) Development of a test battery to enhance safe return to sports after anterior cruciate ligament reconstruction. Knee Surg Sports Traumatol Arthrosc 25: 192-199.

29. Zwolski C, Schmitt LC, Thomas S, Hewett TE, Paterno MV (2016) The utility of limb symmetry indices in return-to-sport assessment in patients with bilateral anterior cruciate ligament reconstruction. Am J Sports Med 44: 2030-2038.

30. Wellsandt E, Failla MJ, Snyder-Mackler L (2017) Limb Symmetry Indexes Can Overestimate Knee Function After Anterior Cruciate Ligament Injury. J Orthop Sports Phys Ther 47: 334-338.

31. Thorstensson C, Petersson I, Jacobsson L, Boegård T, Roos E (2004) Reduced functional performance in the lower extremity predicted radiographic knee osteoarthritis five years later. Ann Rheum Dis 63: 402-407.

32. Gustavsson A, Neeter C, Thomée P, Silbernagel KG, Augustsson J, et al. (2006) A test battery for evaluating hop performance in patients with an ACL injury and patients who have undergone ACL reconstruction. Knee Surg Sports Traumatol Arthrosc 14: 778-788.

33. Harrison EL, Duenkel N, Dunlop R, Russell G (1994) Evaluation of single-leg standing following anterior cruciate ligament surgery and rehabilitation. Phys Ther 74: 245-252

34. Emery CA, Cassidy JD, Klassen TP, Rosyshuk RJ, Rowe BH (2005) Development of a clinical static and dynamic standing balance measurement tool appropriate for use in adolescents. Phys Ther 85: 502-514.

35. Agerberg E, Zätterström R, Moritz U (1998) Stabilometry and one-leg hop tes have high test-retest reliability. Scand J Med Sci Sports 8: 198-202.

36. Brumitt J, Heidersheit BC, Manske R, Niemuth PE, Rauh MJ (2013) Lower extremity functional test and risk of injury in division III collegiate athletes. Int J Sports Ther 8: 216-227.

37. Heidt RS, Sweeterman LM, Carlonas RL, Traub JA, Tekulve FX (2000) Avoidance of soccer injuries with preseason conditioning. Am J Sports Med 28: 659-662.

38. Orr B, Brown C, Hemsing J, McCormick T, Pound S, et al. (2013) Female soccer knee injury: observed knowledge gaps in injury prevention among players/parents/coaches and current evidence (the KNOW study). Scand J Med Sci Sport 23: 271-280.

39. Maffey L, Emery CA (2006) Rationale and evidence for the importance of physiotherapist delivered pre-participation examination. N Am J Sports Phys Ther 1: 176-186.

40. Gjerset A, Annerstedt C, Svendsen T (1997) Sports training Farsta: SISU sports books.

41. Soligard T, Nilstad A, Steffen K, Myklebust G, Holme I, et al. (2010) Compliance with a comprehensive warm-up programme to prevent injuries in youth football. Br J Sports Med 44: 787-793.

42. Trondman M (2005) The youth council's writings. Stockholm: Elanders Gotab AB.

43. Lindblom H, Waldén M, Carlfjord S, Hägglund M (2014) Implementation of a neuromusular training programme in female adolescent football: 3-year followup study after a randomised controlled trial. Br J Sports Med 48: 627-628.

44. Aaltonen S, Karjalainen H, Heinonen A, Parkkari J, Kujala UM, et al. (2007) Prevention of sports injuries: systematic review of randomized controlled trials. Arch Intern Med 167: 1585-1592.

45. Svensson M, Drust B (2005) Testing soccer players. J Sports Sci 23: 601-618.

46. Myer GD, Schmitt LC, Brent JL, Ford KR, Barber Foss KD, et al. (2011) Utilization of modified NFL combine testing to identify functional deficits in athletes following ACL reconstruction. J Orthop Sports Phys Ther 41: 377-387.

47. Söderman K, Werner S, Pietilä T, Engström B, Alfredson H (2000) Balance board training: prevention of traumatic injuries of the lower extremities in female soccer players? Knee Surg Sports Traumatol Arthrosc 8: 356-363. 
Citation: Ytfeldt L, Skenk S, Månsson J, Grönlund MA (2018) Functional Performance in Female Soccer Players Before and After Knee Injury Prevention Training. Physiother Rehabil 3: 161. doi: 10.4172/2573-0312.1000161

Page 8 of 8

48. Hahn T, Foldspang A, Vestergaard E, Ingemann-Hansen T (1999) One-leg standing balance and sports activity. Scand J Med Sci Sports 9: 15-18.
49. Wulff Helge E (1997) Women and sports training. In: Annerstedt C, Gjerset A (eds) Sports training Malmö, SWE: SISU Sports Books. 